\title{
The Problem of Evil Remains Logically Binding
}

\author{
Toby Betenson
}

check for updates

Citation: Betenson, Toby. 2021. The Problem of Evil Remains Logically Binding. Religions 12: 154. https://doi.org/10.3390/rel12030154

Academic Editor: James Sterba

Received: 9 February 2021

Accepted: 24 February 2021

Published: 27 February 2021

Publisher's Note: MDPI stays neutral with regard to jurisdictional claims in published maps and institutional affiliations.

Copyright: (C) 2021 by the author. Licensee MDPI, Basel, Switzerland. This article is an open access article distributed under the terms and conditions of the Creative Commons Attribution (CC BY) license (https:// creativecommons.org/licenses/by/ $4.0 /)$.
School of History, Philosophy, and Social Sciences, Bangor University, Bangor LL57 2DG, UK; t.betenson@bangor.ac.uk

\begin{abstract}
Most contemporary discussions of the problem of evil assume that "logical" formulations of the problem are untenable, and that we should operate with "evidential" formulations instead. I argue that this consensus is founded on a mistake and that there is no legitimate reason to abandon logically binding formulations of the problem of evil. I conclude by arguing that, though it is possible to formulate a genuinely "evidential" problem of evil, logical formulations of the problem of evil are preferable in all cases.
\end{abstract}

Keywords: problem of evil; Mackie; Plantinga; Sterba; logical; evidential

Most philosophers nowadays appear to think that "logical" formulations of the problem of evil are untenable. And so the titular question of Sterba's (2019) book-“'Is a Good God Logically Possible?"-might cause raised eyebrows amongst a generation of philosophers educated under this consensus. Has that question not been settled? Haven't we moved on? Hasn't Plantinga shown that asserting an outright logical incompatibility between the existence of God and the existence of evil is an impossible task, and so we should deploy "evidential" formulations of the problem of evil instead?

This consensus seems to be a consequence of the perceived refutation of Mackie (1982) canonical presentation of the logical problem of evil by, amongst others, Alvin Plantinga (1977). Mackie's original formulation has three original propositions:

1. God is omnipotent.

2. God is omnibenevolent.

3. Evil exists.

To which he adds:

4. "Good is opposed to evil in such a way that a being who is wholly good eliminates evil as far as he can."

5. "There are no limits to what an omnipotent being can do." (Mackie 1982, p. 150)

Mackie claimed that the first three propositions form a logically inconsistent set, given the addition of the "quasi-logical rules" of 4 and 5, and therefore that this "logical problem" presents itself to any theist for whom these premises are prima facie true. In response, Plantinga pointed out that there is still no explicit contradiction (of the form " $\mathrm{P} \& \sim \mathrm{P}^{\prime}$ ) within this set, even with Mackie's additions. Furthermore, in order for there to be an implicit contradiction within the original three propositions, the additional "quasi-logical rules" must be necessarily true, which they are not. Plantinga deploys his "Free-Will Defence" to show this, which has been discussed extensively elsewhere; I will not add to that discussion here.

Since Mackie's formulation of the logical problem of evil seemed doomed to failure, philosophers (Rowe 1979) were keen to shift towards "evidential" formulations of the problem of evil. That is, versions of the problem that do not rely on a notion of logical incompatibility between God and evil (or God and certain types of evil), but instead rely on a non-deductive probabilistic argument based on the perception that the evils of the world render it incredibly unlikely that God exists. This shift was, I think, a mistake. Plantinga has not given us sufficient reason to abandon all logical formulations, even if 
he has successfully shown that the most basic version-in the form of Mackie's original formulation -will not cut it. It is still quite possible to formulate logical formulations of the problem of evil that rely upon some notion of deductive validity, or logical inconsistency, as Sterba's book illustrates. I will argue that we can and should do so, and that we have no good reason to shift towards "evidential" formulations of the problem of evil. I will show that any contrast between logical and evidential formulations either a) fails to represent a significant difference between the two formulations, such that the two formulationsevidential and logical—are to be treated any differently, or else b) fails to offer a sufficient motivation to warrant shifting from logical to evidential formulations. The conclusion of my arguments will be that we have no good reason to dismiss logical formulations of the problem of evil, formulations that rely upon a strong sense of deductive or logical inconsistency, and are therefore logically binding. In my closing remarks I conclude that logical formulations are the most appropriate way to tackle the problem of evil.

As such, my purpose in this paper is to defend the approach of Sterba's argument, rather than the argument itself. That is, I argue that we can and should formulate the problem of evil, and any arguments based thereon, in a "logical" rather than "evidential" form. Posing the problem of evil in such a "logical" form is best suited to the task of "clarifying and if possible reconciling" a set of beliefs, which I take to be the underlying intention of any discussion on the problem of evil.

\section{Deductive versus Inductive Formulations}

The starting point here is what followed from the debate between Alvin Plantinga and J. L. Mackie. The perception is that Plantinga showed Mackie's logical formulation to not be deductively valid, and therefore any future formulations of the problem of evil would need to abandon the aspiration towards deductively valid argument. Inductive argument would present the next best alternative, and this is what evidential formulations of the problem of evil aspire to achieve.

I will argue that Plantinga's response, though remaining a successful refutation of Mackie's formulation, does not offer us sufficient motivation to warrant shifting away from all logical formulations of the problem of evil. We can easily reformulate the problem of evil to evade Plantinga's challenge to the problem's validity, even if his challenge would remain a challenge to the soundness of any argument based on the problem. I will then move on to questioning some other motivations for shifting towards evidential formulations, those concerning the recognition that a premise within the problem of/argument from evil contains a crucial inductive step. Because of the presence of this inductive step, it is concluded that the argument from evil is better formulated as an inductive argument. I will argue that this is a mistake.

Having dealt with the motivations for shifting from logical to evidential formulations of the problem of evil, I will conclude by pointing out that no significant shift has really occurred. Things have always been as they are now; the old-fashioned logical argument was always based upon inductive "evidence", and the new-fangled evidential formulations are just as deductively binding as their logical forebears ever were. We therefore have no reason to abandon logically binding formulations of the problem of evil.

\subsection{Plantinga Evaded}

One of Plantinga's central assumptions in responding to Mackie's formulation of the problem of evil is that any proposition that is additional to the original three propositions of the "inconsistent triad" (God is omnipotent, God is omnibenevolent, evil exists) must be "necessarily true" if it is to expose an implicit contradiction and thus render Mackie's argument deductively valid (Plantinga 1977, p. 13). But the special requirement that these additions be necessarily true is only a product of needing to go looking for an implicit contradiction. If we reformulate the problem of evil in such a way that the contradiction is explicit or formal, then we lose this special requirement. The first thing to ask, therefore, is why on earth we should feel bound to Mackie's formulation? We can easily reformulate the 
problem of evil in such a way that a contradiction is made explicit or formal. The easiest way to do this would be to build the additions into the premises from the outset, expressing both the relevant divine properties and the perceived incompatibility between God and evil, giving something like:

A1. A maximally-good, maximally-powerful creator of the universe would not create or permit any evil in its creation.

\section{A2. Some evil exists.}

Additional modifications are obviously available, such as "gratuitous", "horrendous", etc., but they are not relevant to the point that I am making. If we now add the proposition "A maximally-good, maximally-powerful creator of the universe exists", then we could have a straightforwardly inconsistent set. The contradiction would be formal, in this case, since it is capable of yielding a contradiction of the form "P \& $\sim \mathrm{P}$ " via the application of logical rules. With a formal contradiction, we therefore have no need to go looking for an implicit contradiction, and therefore lose the requirement that any of these premises, or any component thereof, be necessarily true. Plantinga's response, in the form of his free will defense, would no longer threaten the deductive validity of the problem of evil, for it would only (at most) show that one of the premises is not necessarily true, and that is an issue of soundness, not validity.

Why, then, should we not adopt this formulation of the problem of evil? Well, it might be argued that, whereas Mackie's formulation moves from propositions that are readily prima facie acceptable to most theists, this formulation is not so obviously acceptable. Though most theists would readily consent to God being both maximally-good and maximally-powerful, fewer (at least if Plantinga's response is anything to go by) would so easily consent to the notion that, because of this, God would not permit any evil in His creation. Any argument that is based on this formulation of the problem of evil would hold little weight with such a theist, and this might be considered a significant failure, if the intention of the problem of evil were to provide some foundation for an argument from evil that would have some persuasive power for all theists.

But this is not a very good reason to reject the formulation. After all, Mackie's formulation included a claim that not all theists were willing to accept; namely, that evil existed. The history of the discussion of the problem of evil is replete with examples of theists who have denied that this premise was true: Alexander Pope's Essay of Man comes to mind, or else the Augustinian notion of privatio boni. The point is not whether the premises within the argument from evil are ultima facie acceptable to all theists, but only that the premises are prima facie true to most theists most of the time (or even some theists some of the time). And it certainly seems to be prima facie true for most theists that a maximally-good, maximally-powerful God would prevent any evil in His creation: otherwise we would struggle to account for the intuitive contradiction within Epicurus's Old Riddle.

That the premise is not necessarily true is not a threat to the validity of the underlying problem, only to the soundness of any argument that is based upon it. That the problem is deductively valid entails that it remains a "logical" formulation, and certainly remains logically binding: no one can consistently maintain the truth of all three propositions in this inconsistent set. This is all the problem of evil ever sought to achieve- to offer the theist the task of "clarifying and if possible reconciling" their set of beliefs (Mackie 1982, p. 150) —and as such ought to be considered successful in this form.

And yet, there is a sense in which those who call for a shift to evidential formulations of the problem of evil are inclined to think otherwise. The motivation for this seems to stem from a willingness to adopt a notion of "logical" argument that extends Plantinga's original requirement that any premises added to Mackie's original three propositions be necessarily true to every premise in the argument from evil. This is a mistake; I will now show why. 


\subsection{Post-Plantinga: William Rowe and Michael Tooley}

Here is William Rowe's formulation of the argument from evil:

R1. There exist instances of intense suffering which an omnipotent, omniscient being could have prevented without thereby losing some greater good or permitting some evil equally bad or worse.

R2. An omniscient, wholly good being would prevent the occurrence of any intense suffering it could, unless it could not do so without thereby losing some greater good or permitting some evil equally bad or worse.

R3. [Therefore] There does not exist an omnipotent, omniscient, wholly good being. (Rowe 1979, p. 336)

Rowe concedes Plantinga's point that it remains logically possible that any instance of evil is in fact justified by greater goods, etc., but argues that it nevertheless remains reasonable to believe otherwise. It is very difficult to see what possible good could result from a deer suffering a painful death over the course of five days after having been burnt in a forest fire. What good could be achieved by a five-day death that could not be achieved by a four-day death, for example? Rowe concludes that the existence of such evil remains evidence against the existence of God, even if it cannot count as conclusive proof.

Rowe still considers his argument valid (Rowe 1979, p. 336), which it is, but concedes that it is not necessarily sound, for premise R1 is not necessarily true. This concession alone seems to have motivated the shift towards evidential formulations of the argument from evil. But given what I have said in the previous section, why should we consider this a threat to the logical problem of evil? All that Rowe allows to be open to doubt is whether a premise within the argument is true or not; that is, he doubts the soundness of the argument, but not the validity of the underlying problem. It remains the case that if there are instances of intense suffering such that an omnipotent, omniscient being could have prevented them without thereby losing some greater good or permitting some evil equally bad or worse, and R2 is true, then there cannot exist such an omnipotent, wholly-good being. The theist must still deny one premise here, just as the logical problem maintains.

So if Rowe thinks the potential falsity of one premise within his argument is sufficient to warrant abandoning "logical" formulations of the problem of evil, then he seems to think that any "logical" formulation must not only be valid, but must also be made up of entirely necessarily true premises. And he is not alone in thinking this, it seems. Consider, for example, Michael Tooley's summary. (It is important to acknowledge here that Tooley is writing for the purposes of a survey article, so I take his words only to be representative of a general consensus view, rather than specifically his own. None of what I say here challenges the excellent work Tooley has done in the field of inductive arguments from evil: I question only the implied claim that deductive formulations are no longer viable or desirable, and specifically the claim that they are no longer viable or desirable for a certain set of reasons.)

How would one go about establishing via a purely deductive argument that a deer's suffering a slow and painful death because of a forest fire, or a child's undergo [sic] lingering suffering and eventual death due to cancer, is not logically necessary either to achieve a greater good or to avoid a greater evil? [...] If a premise such as [R1] cannot, at least at present, be established deductively, then the only possibility, it would seem, is to offer some sort of inductive argument in support of the relevant premise. But if this is right, then it is surely best to get that crucial inductive step out into the open, and thus to formulate the argument from evil not as a deductive argument for the very strong claim that it is logically impossible for both God and evil to exist, (or for God and certain types, or instances, of evil to exist), but as an evidential (inductive/probabilistic) argument for the more modest claim that there are evils that actually exist in the world that make it unlikely that God exists. (Tooley 2015) 
If we were to read this in an unsympathetic way, we could respond with an incredibly trivial answer here. In order for the problem of evil to be considered "logical", we want a "purely deductive" argument that establishes the truth of a premise like R1; that is, R1 must be the product of a deductively valid argument that contains no inductive premises or steps. This is, strictly speaking, an incredibly easy thing to achieve. For example: "One plus one equals two; if one plus one equals two then R1 is true: therefore, R1 is true." This is a deductively valid argument that establishes the truth of R1, and it contains no obviously inductive steps, but it is not a good argument and is clearly not what we are looking for. What we want is for R1 to be supported by an argument that is purely deductively valid (i.e., including no inductive steps), relevant, and sound. This, as Tooley is aware, is a very difficult thing to achieve. As a result, he concludes that the problem of evil ought not to be formulated as a logical problem.

What emerges is a simple claim: If a premise within an argument cannot be established "purely deductively", then the argument is better formulated as an inductive (evidential/probabilistic) argument. I take this to be the consensus view when it comes to the problem of evil. It seems that, according to the consensus view, in order for an argument from evil to the non-existence of God to be considered "logical" it must be deductively valid and composed of premises that are themselves the product of deductively valid arguments; that is, they must include absolutely no inductive steps. I will call this feature "deductively valid all the way down" (DVATWD), and it seems to me to be a very bad criterion for what we are to consider "logical" arguments.

I will argue that DVATWD is an unreasonable demand to place upon what we are to consider "logical" arguments. It restricts the potential list of "logical" arguments to a vanishingly small number of largely uninteresting tautologies.

\section{"Logical" Arguments}

It seems to me that whether an argument is logical or not is primarily dependent upon deductive validity. And not all logical arguments are good arguments: you can have bad logical arguments, arguments that are valid but composed of junk premises. Good arguments require validity and true premises, and whether premises are true or not is an issue of soundness, not validity. Sound arguments might be a strong indication of good arguments, and a certain indication (by definition) of logical arguments, but that does not mean that only sound arguments are logical arguments.

It seems that Rowe and Tooley et al. disagree with this point. They require that, in order for the problem of evil to be considered "logical", it and its premises must be deductively valid all the way down. This entails that logical arguments are only those that contain absolutely no inductive steps. I will call this the "consensus definition". This cannot be correct, for it places an utterly unreasonable demand upon what we can consider to be "logical" arguments.

Consider, for example, what we would make of this good logical argument:

1. All men are mortal.

2. Socrates is a man.

3. Therefore, Socrates is mortal.

The "Socrates is mortal" example is an archetypal "logical" argument. And yet, is it deductively valid all the way down? Consider 1: "All men are mortal." How would we establish "via a purely deductive argument" the truth of this premise? Well, one might wish to go down the route of claiming that "by definition, human beings are mortal", but I do not think that this is commonly what people would take to be adequate justification for the truth of this premise. If this premise is true, then it is because all the evidence available to us tells us that it is so! It is because every human we have ever known of has died that we conclude that "all men are mortal". If tomorrow we find a human that cannot die, we change our view; this is a logically possibility. It is an empirical claim, and therefore relies, ultimately, upon an inductive step. The same applies to 2, "Socrates is a man", since this is also an empirical claim. Therefore, this archetypal logical argument is not deductively 
valid all the way down, and as such ought to be, according to the consensus definition, formulated as an inductive argument. This is an "evidential argument for the mortality of Socrates".

But it is absurd not to call the Socrates argument "logical". Therefore, the consensus definition is incorrect.

Note that the same applies if we include a DVATWD premise. Consider:

1. All bachelors are unmarried men.

2. Mike is a bachelor.

3. Therefore, Mike is an unmarried man.

This is a deductively valid argument, of the same form as "Socrates", but where we had a logically contingent claim of "all men are mortal", we now have a logically necessary claim: "All bachelors are unmarried men." This is necessarily true, it is deductively valid all the way down. But premise 2 is not. Though Mike might actually be a bachelor, it could never be necessarily true that he would be, and it could never be established "purely deductively" that he is. Again, 2 is an empirical claim, and as such cannot be deductively valid all the way down. Once again, according to the consensus definition, this is not a logical argument. We should "get our inductive step out into the open" and formulate this as an inductive argument for the conclusion that Mike is (probably) an unmarried man.

What can be considered a "logical" argument, according to the consensus definition? The answer is clear: hardly any argument. Specifically, only those arguments that are deductively valid all the way down. That is, only arguments that are deductively valid, whose premises are themselves deductively valid, etc., and that contain no inductive steps. Which means, ultimately, only those arguments that are composed entirely of necessary truths. This seems to have extended Plantinga's original requirement that any additional premises be necessarily true to apply to all premises within the problem of evil, whatever its form. To my mind, this is an unreasonably strict standard of "logical" argument.

Surely, if we mean anything at all by calling an argument "logical", we mean only that it is deductively valid. Whether its premises happen to be true or not, potentially true or not, possibly false or not, is entirely beside the point; those are issues of soundness. That Plantinga has successfully shown that a premise within the argument from/problem of evil is possibly false makes absolutely no difference to the status of the argument/problem as being a "logical" argument/problem.

\section{3. "Evidential" Arguments}

Having said all that, we might still be intuitively inclined to call it an "evidential" argument, in that (a) it is an argument for the non-existence of God, and therefore counts as evidence against the sort of cumulative case argument for the existence of God presented by Richard Swinburne (2004), and (b) it is an argument for the non-existence of God that is based on evidence. But though there is clearly an ambiguity in how we describe evil as "evidence against the existence of God" (Tooley 2015), with some philosophers no doubt taking this to mean "an argument based upon evidence" and others as "an argument counting against the probability of the existence of God", this linguistic carelessness (as Bishop and Perszyk (2011, p. 111) call it, "terminologically inept") does not justify abandoning the notion that the problem of evil can be a logically binding problem, relying upon a notion of deductive logical inconsistency. Because nothing has really changed here. The logical argument from evil always counted as "evidence against" God's existence, but that (alone) did not render it an "evidential" argument. Furthermore, the logical argument from evil was always based upon "evidence", in that even Mackie's formulation contained the claim that "evil exists", and, as I have mentioned, this was always a disputed claim.

We are left without cause to shift away from deductive formulations of the problem of evil towards inductive versions, and so no cause to abandon logically binding formulations of the problem of evil. 


\section{Strong versus Weak Conclusions}

Perhaps there is another option to support evidential formulations of the problem of evil over logical formulations along these lines, in terms of contrasting the differing force of their respective conclusions. Perhaps the relevant difference between logical and evidential formulations of the problem of evil is not primarily about deductive or inductive reasoning, but instead that logical formulations assert the strong conclusion that the existence of evil entails the logical impossibility of God's existence, whereas evidential formulations only assert the weaker conclusion that the existence of evil renders God's existence unlikely. Logical formulations express necessity, whereas evidential formulations only express contingency. For some, this might be the most intuitive option, but although it sounds like a reasonable distinction to draw, the distinction cannot be sensibly maintained and quickly collapses into the already-discussed distinction between deductive and inductive formulations; it can therefore be dismissed with the same criticisms. I will not repeat those criticisms excessively but will focus my efforts into showing how this option collapses into the previous.

\section{Reducing "Strong versus Weak" to "Deductive versus Inductive"}

What is it to say that the existence of evil renders God's existence unlikely, rather than impossible? Given that this statement is taken as the conclusion of an argument, there are two possibilities: Firstly, one could be asserting that one's argument is not necessarily deductively valid, even though one's premises are true. This would leave the argument from evil as an inductive-style argument whereby the truth of the premises does not confirm the truth of the conclusion; the argument is not based upon any notion of logical inconsistency. This seems to have been what those who followed Plantinga were seeking to assert, but they instead fell back into presenting the second possibility: Second, one could be asserting that though the argument is deductively valid, one or more of the premises are not necessarily true. Therefore, the conclusion is true only to the extent that the premises are certain. The premises are not certain, though likely, and therefore the conclusion is limited to a probabilistic claim. This seems to be what Rowe et al. opted for.

The first possibility is a viable option and would quite genuinely, I think, count as a properly "evidential" argument from evil to the non-existence of God; it is one that I will consider in my concluding remarks, since it represents what I take to be the most legitimate claim to an "evidential" formulation of the problem of evil. It is a viable option, only no one seems to choose it. Instead, we go for deductively valid formulations of the problem of evil and then debate the probabilistic truth of the premises. That is, we opt for the second possibility. This leaves the conclusions of these "evidential" arguments as being logically binding conditionally upon the truth of their premises. This leaves these formulations in precisely the same position as any other deductive argument, and therefore given that the "logical" alternative is purported to be a "necessary" conclusion (rather than a contingent one), the difference between "logical" and "evidential" formulations is going to boil down to, once again, the requirement that some or all components within the argument be DVATWD.

Requiring that any component of an argument be DVATWD is a mistake, as I have already argued. This new option now repeats this mistake, so the same criticism applies. If the key difference between logical and evidential formulations is understood to be the necessary or non-necessary status of their conclusions, and each variation is understood to be deductively valid, then the necessary/non-necessary status of their respective conclusions will boil down to the necessary/non-necessary status of their premises. Having necessarily true premises is not something that we should ask of a logical argument, so insisting on its failure on this basis is untenable: it would, once again, warrant no shift towards evidential formulations.

The viable alternative for evidential formulations would be to construct a genuinely inductive argument from evil to the non-existence of God, one in which the truth of the premises does not logically compel the truth of the conclusion. This, however, would return 
us to our original distinction, since logical formulations, by contrast, would be deductive arguments. This, then, seems to be the only sensible distinction to be drawn between "logical" and "evidential" formulations; that of "deductive" versus "inductive" arguments.

Although much of what I have said should render logical formulations perfectly viable under this distinction, nothing I have said so far rules out the viability of genuinely inductive arguments from evil to the non-existence of God, and it might be that these are preferable to deductive formulations of the problem of evil. I will now argue that they are not preferable.

\section{Genuinely "Evidential" Arguments}

For all that I have said against the distinction between logical and evidential formulations of the problem of evil, I think that there is a relevant and helpful distinction to be drawn between logical and evidential arguments generally. But this distinction cannot just be that evidential arguments are deductive arguments with evidence-based or otherwise non-necessary premises. The relevant distinction must lie in the contrast between "inductive" and "deductive" argument forms. This distinction is a genuine distinction, and it is helpful because some things are more appropriately dealt with via inductive arguments, whilst some are better dealt with via deductive arguments.

I illustrate this with an example. Imagine that I am trying to convince someone of the ineffectiveness of homeopathy. I could offer a strictly evidential/inductive argument:

E1. Study 1 shows that homeopathy is ineffective.

E2. Study 2 shows that homeopathy is ineffective.

E3. Study 3 shows that homeopathy is ineffective.

$\mathrm{E}[\ldots] .[\ldots]$

E10. Study 10 shows that homeopathy is ineffective.

E11. Therefore, homeopathy is ineffective.

This is a strictly inductive argument. It is certainly reasonable to believe the conclusion based upon the premises (especially if the premises are supplemented with the addition of further studies showing homeopathy's ineffectiveness), and it is intuitively clear that the premises increase the probability of the conclusion, but no one is logically bound to accept the conclusion even though they might accept the truth of the premises. Quite feasibly my opponent could accept the truth of all my premises and yet reject my conclusion. All I could say in response, at this point, is something akin to "you are being unreasonable", or "you are ignoring the evidence", etc. But these will not necessarily be conclusive or convincing responses.

Alternatively, I could offer a logical argument for the ineffectiveness of homeopathy, with the aim of showing that those who believe that homeopathy is effective believe a logically inconsistent set of propositions:

P1. Homeopathy is effective.

P2. If homeopathy is effective, then it will be effective under reasonable experimental conditions.

P3. Homeopathy is not effective under reasonable experimental conditions.

One of these propositions must be rejected, since the set is logically inconsistent, and yet all three seem to be at least prima facie true for those who believe that homeopathy is effective (and are aware of the evidence against it). If I am so inclined, I can convert this "problem of homeopathy" into an argument for the ineffectiveness of homeopathy by adding the conclusion: "Therefore, homeopathy is not effective." But this conclusion would only be true to the extent that I was sure that P2 and P3 are true. This logical formulation lays no claim to any of its components being necessarily true, or DVATWD, and is quite open about the fact that P3 is an overtly empirical claim. But it is clearly distinct from the evidential/inductive formulation just mentioned, and the relevant difference is that this 
logical formulation relies upon a notion of logical inconsistency. My opponent cannot accept the truth of my premises yet reject the truth of my conclusion. If they wish to maintain a denial of my conclusion, then they must, with the force of a logical must, reject one of my premises, in this case P2 or P3. This logical formulation is unavoidable, whereas the evidential formulation could potentially be left unresolved.

It might be that the practical difference between these two options does not amount to all that much, since in the first instance we would end up debating the strength of the (inductive) entailment between the premises and the conclusion, and in the second we would end up debating the truth of the premise that asserts this entailment outright. But it would remain the case that there is an important theoretical distinction, and it seems to me that, depending on the beliefs of my interlocutor, one or other argument form might be more appropriate. If, for example, my interlocutor is simply ignorant of the many studies that show homeopathy to be ineffective, then presenting a list of premises in an inductive argument might be more persuasive than constructing a deductive argument out of premises that they are not in a position to appreciate the truth of. If, on the other hand, I know that my interlocutor is fully aware of the many studies that show the ineffectiveness of homeopathy-the "evidence" is fixed, as it were, as a common ground-then it will be clear to me that simply adding to the list is not going to get to the root of the disagreement between us. Instead, it might be more helpful for me to present a deductively valid problem to them, and pinpoint precisely what it is that they reject in my argument. If it is simply the strength of the inductive entailment, as expressed in premise 2, then at least we now know where we stand.

For many such disagreements, where the "evidence" is not fixed or known to all parties, offering inductive-style arguments in the form of adding further premises to the list of propositions that, on balance, increase the probability of one conclusion or another is an entirely appropriate way to go about persuading people of things. If, however, the evidence is shared as a common ground, then adding to the list is not so helpful. The disagreement is then more logical in nature; it is about "what follows from what", "what entails what", and as such is better dealt with via deductive arguments. In a deductive argument, you can still debate the truth of the premises, but at least now you will know where your disagreement lies.

\section{Evidential Formulations Are Inappropriate for the Problem of Evil}

An important point to recognize here is that though it is clearly suitable to debate the effectiveness of homeopathy in evidential terms, it is not so clearly the case with the problem of evil. We can generate evidence for or against the proposition of homeopathy's effectiveness without difficulty, but it is very difficult to see how we would go about generating any more or less evidence for the comparable issues in the problem of evil. Everyone is surely aware that there have been instances of terrible evil in the world and that more are likely to come. Unlike the homeopathy example, it is not as if any further evidence is likely to have any effect on the outcome of the debate concerning the problem of evil. This calls into question the suitability of evidential formulations to tackle such a problem.

In the case of homeopathy, we are (arguably) debating the evidence; we are asking an overtly evidential question, "Is it the case that homeopathy works?", so this question is reasonably dealt with evidentially. However, in the case of the problem of evil, we are not debating the evidence; there is no further evidence that we can bring in to help us find an answer to this question; we are debating what we should believe on the basis of the evidence. The issue is about "what follows from what", and so we must simply reflect, $a$ priori if you will, on our set of beliefs and try to establish a coherent set. This is not a task that further evidential work can help with. Evidential formulations of the problem of evil, therefore, seem inappropriate. 


\section{Conclusion: The Problem of Evil Remains Logically Binding}

We have no good reason to stop formulating logically binding formulations of the problem of evil. It seems to me that we have simply been careless in taking the nonnecessary truth of a premise within an argument as good reason to call that argument "evidential" rather than logical, and have further concluded from this that, since the argument is merely "evidential" and inductive, the conclusion is not logically binding. This is a mistake. Valid, logically binding arguments only ever established the truth of their conclusions conditionally upon the truth of their premises, and this remains the case in the argument from evil. All that has happened, with responses such as Alvin Plantinga's, is that the premises within the argument have been shown to be not necessarily true. But this was always the case.

There is, therefore, nothing preventing us from operating with a simple and logically binding formulation of the problem of evil that can achieve the aim of forcing the theist to "clarify, and if possible reconcile" (Mackie 1982, p. 150) their set of beliefs. And this is precisely what I see Sterba's argument to be: an argument that forces the theist to reconcile the set of beliefs that includes beliefs about God, beliefs about the existence of evil and suffering, and beliefs about ethical and political rights and principles. He presents a series of arguments to show that there is no consistent set of beliefs here, and as such, belief in God is not compatible with the existence of evil: or, as he puts it: "All three sub-arguments conclude to the logical impossibility of God." (Sterba 2019, p. 199)

The success of that formulation will depend on the truth of the premises, clearly, but there is virtue inherent in presenting the argument in this logical form. It forces us to find reason to reject the conclusion, if we deny it. It allows us to clearly pinpoint where and to what extent we consider the argument to break down, if we do, and therefore precisely the reasons why we might not accept the conclusion on the basis of that argument. It is this that allows us to clarify and reconcile our set of beliefs.

For example, Sterba argues: "there is a logical contradiction between the existence of God, our moral requirements, and what would have to be God's widespread failure to prevent the loss of significant freedoms in our world resulting from moral actions." (Sterba 2019, p. 77) As such, the claim is that the following set is inconsistent: God's existence, our moral requirements, and the evils of the world. The argument, so stated, is valid, so this is a "logical" problem of evil. It might not necessarily be sound. It can be resolved by rejecting one of the propositions. So at what point does the theist disagree? Denying the existence of God is not the one (as a theist); denying the existence of evil is also not likely to be the one (though it remains an option ... ); the obvious candidate is "our moral requirements". And not, it is likely, in themselves; that is, the theist probably will not reject the moral requirements as stated. The resolution would come in the form of rejecting that these moral requirements-our moral requirements-really apply to God in a sufficiently unaltered form. "The ways of the most high are not our ways" (Kant 2001, p. 27), it might be claimed: "Sunt superis sua iura! quid ad caelestia ritus/Exigere humanos diversaque foedera tempto?"

What "evidence" can help us answer this question? What "inductive step" or "probabilistic inference" can do any work? This would seem to miss the point. This is a question about "what follows from what", calling for suitably informed philosophical reflection.

For example, for me, the argument breaks down at the analogy between the obligations of a good God and those of an "ideally just political state". As Sterba says, "... my logical argument against the existence of God just rests primarily on (1) exceptionless minimal components of the Pauline Principle (Moral Evil Prevention Requirements I-III), and (2) the analogy of an ideally just and powerful state." (Sterba 2019, p. 169) When I reflect on these moral requirements, I find little to dispute in them, but would hesitate to apply them analogously to God-at least not straightforwardly. One reason for questioning the analogy might be that part of the essence of an "ideally just state" would seem to be its sovereign authority having been granted, ultimately, by the people. I take this to be a fairly foundational cornerstone of contemporary political philosophy, one that does no 
small amount of foundational work for our concepts of rights in general, and whilst this was clearly not always the case, it is surely a hinge proposition around which most of our understanding of political authority now swings: A political state whose sovereign authority does not come from democratic mandate is not an ideally just political state.

But can we say the same of God's sovereign authority? Must we? It is not clear to me that we must. It seems to me that whatever sovereign authority God might have, it is decidedly nothing like the sovereign authority of an ideally just political state. Who gave God permission to create the universe? Who could? And if someone claimed to, they might invite the response of "Where were they when God created the Heavens and the Earth?" etc.

Can we creatures say, like a Pythonesque peasant, "well I didn't vote for you"? "Come and see the violence inherent in the system! Help! Help! I'm being repressed!" This is not (only) a rhetorical point; it is a conceptual point. The sovereign authority of an "ideally just political state" can (possibly must) come from the will of the people who make up its body, because the people make up that political state. The sovereign authority of God need not (possibly cannot) come from the will of the people, for the people do not "make up" what God is-if they were to, then it would not be clear that that is properly called God.

Of course, it matters not only that the analogy breaks down, but that it breaks down in a way that is relevant and significant for the argument. I think that is so in this case. Given the essential links between "authority" and "obligation", a significant change in one seems likely to affect the other. Legitimate political authority comes with obligations for those who wield it - the failure to uphold these obligations illegitimizes the authority. Legitimate political authority also might yield obligations for those who are subject to it. So, either way, whatever is meant by the "ideally just political state" will have significant consequences for any obligations that follow.

So, are God's obligations "like" the obligations of an ideally just political state? It is not clear to me that they are, because the legitimacy of God's authority is not "like" the legitimacy of political authority. And so the grounds for the obligations of an ideally just political state are not the same as the grounds for God's obligations (whatever they might be). But whilst I disagree with the argument on this one small point, I make this point as an endorsement of the logical approach. It is only because I am pushed to find or resolve an apparent contradiction that I find the conceptual disanalogy. This is how I "clarify and reconcile" my set of beliefs. This is not the consequence of an evidence-based or probabilistic critique, but only of a suitably informed philosophical reflection on "what follows from what". I take logical formulations of the problem of evil to be the best means to this end.

Funding: This research received no external funding.

Conflicts of Interest: The author declares no conflict of interest.

\section{References}

Bishop, John, and Ken Perszyk. 2011. The normatively relativised logical argument from evil. International Journal for Philosophy of Religion 70: 109-126. [CrossRef]

Kant, Immanuel. 2001. On the Miscarriage of all Philosophical Trials in Theodicy. In Religion and Rational Theology. Translated and Edited by Allen W. Wood and George Di Giovanni. Cambridge: Cambridge University Press, pp. 24-37.

Mackie, John L. 1982. The Miracle of Theism: Arguments for and against the Existence of God. Oxford: Clarendon Press.

Plantinga, Alvin. 1977. God, Freedom, and Evil. Grand Rapids: Eerdmans.

Rowe, William L. 1979. The Problem of Evil and Some Varieties of Atheism. American Philosophical Quarterly 16: 335-41.

Sterba, James P. 2019. Is a Good God Logically Possible? London: Palgrave Macmillan.

Swinburne, Richard. 2004. The Existence of God, 2nd ed. Oxford: Oxford University Press.

Tooley, Michael. 2015. The Problem of Evil. Stanford Encyclopedia of Philosophy. Available online: http://plato.stanford.edu/entries/evil/ (accessed on 9 February 2021). 